\title{
Obesity-induced Diabetes (Diabesity) in C57BL/KsJ Mice Produces Aberrant trans-Regulation of Sex Steroid Sulfotransferase Genes
}

\author{
Edward H. Leiter and Harold D. Chapman \\ The Jackson Laboratory, Bar Harbor, Maine 04609
}

\begin{abstract}
The diabetes $(d b)$ gene is a recessive obesity mutation in the mouse capable of producing diabetes only through interaction with heretofore undefined modifiers in the genetic background of certain inbred strains. Here we identify the genetic map locations of androgen and estrogen sulfotransferase genes important in maintaining the balance of active sex steroids in the liver. The Std locus encoding dehydroepiandrosterone sulfotransferase was mapped to proximal Chromosome 7, and the Ste locus encoding estrogen sulfotransferase was mapped to Chromosome 5. The $d b$ mutation in the diabetes-susceptible C57BL/KsJ strain aberrantly regulated mRNA transcript levels from these two loci. Hepatic Ste mRNA transcripts were increased from undetectable levels in normal males and females to high levels in $d b / d b$ mice of both sexes. An anomalous suppression of $S t d$ transcription was observed in $d b / d b$ females, but not in normal females. These reciprocal changes in mRNA concentrations in mutant females were reflected by an induction of a high affinity estrogen sulfotransferase activity and a concomitant loss of dehydroepiandrosterone sulfotransferase activity. These $d b$ gene-elicited effects were specific for the sex steroid sulfotransferases since other potential sex steroid metabolizing enzymes ( phenol sulfotransferase, sex steroid sulfohydrolase, and UDP-glucuronyltransferase) were unaffected. These aberrant changes would virilize hepatic metabolism in females by increasing the ratio of active androgens to estrogens. In human females, non-insulin-dependent diabetes mellitus often develops when visceral obesity and hyperinsulinemia are associated with hyperandrogenization. This study demonstrates that background modifier genes interacting deleteriously with an obesity mutation are not necessarily defective alleles. Rather, some are functional genes whose regulation has been altered by pleiotropic effects of the obesity gene. (J. Clin. Invest. 1994. 93:2007-2013.) Key words: mice • diabetes • sulfotransferases • androgens $\bullet$ estrogens
\end{abstract}

\section{Introduction}

Abdominal ( or visceral ) obesity in humans is a genetically controlled phenotype constituting a major risk factor for develop-

Address correspondence to Dr. E. H. Leiter, The Jackson Laboratory, 600 Main Street, Bar Harbor, ME 04609.

Received for publication 2 August 1993 and in revised form 21 December 1993.

J. Clin. Invest.

(c) The American Society for Clinical Investigation, Inc. 0021-9738/94/05/2007/07 \$2.00

Volume 93, May 1994, 2007-2013 ment of non-insulin-dependent diabetes mellitus (NIDDM) ${ }^{1}$ (1). Although $\sim 80 \%$ of NIDDM patients are obese, most obese humans do not develop NIDDM. Since NIDDM is genetically heterogeneous, it is presumed that an obese individual must inherit additional mutations producing dysregulation of normal glucose homeostasis to be susceptible to obesity-induced NIDDM. The term "diabesity" has been coined to describe animal models in which obesity is clearly intertwined with the initiation of diabetes (2). Mice homozygous for the autosomal recessive obesity mutation, diabetes ( $d b$, Chromosome 4), provide model systems for dissecting the polygenic interactions required for initiation of a diabesity syndrome (3). On certain inbred strain backgrounds (C57BL/KsJ, C3H.SW/ $\mathrm{J})$, the $d b$ mutation is diabetogenic in mice of both sexes. On other inbred strain backgrounds (C57BL/6J, 129/Lt), $d b / d b$ mice of both sexes, although extremely obese, are diabesity resistant. On the $\mathrm{C} 3 \mathrm{HeB} / \mathrm{FeJ}$ inbred background, diabesity is male sex limited. Orchiectomy blocks diabetes development in $\mathrm{C} 3 \mathrm{HeB} / \mathrm{FeJ}-d b / d b$ males, while ovariectomy renders $\mathrm{C} 3 \mathrm{HeB} / \mathrm{FeJ}-d b / d b$ females diabetes susceptible (4). Estrogens, which facilitate hepatic glucose uptake and storage in rodents, provide the most effective means of suppressing excessive hepatic glucose output in susceptible mice (5). Given these gender-associated aspects of diabesity control, we hypothesized that genes controlling the balance of active estrogens to androgens in the liver were logical "candidate" genes required for conversion of an obesity syndrome into a diabesity syndrome.

Diabesity elicited by the $d b$ mutation on the C57BL/KsJ (BKs) inbred background has been associated with aberrant hyperandrogenic shifts in hepatic sex steroid metabolism (4, 6). Sex steroid sulfotransferases (ST) are cytosolic enzymes catalyzing the transfer of a hydrophilic sulfate moiety onto androgens and estrogens (Fig. 1). Sulfoconjugated androgens and estrogens do not bind to their receptors. Sulfurylation therefore represents a mechanism for intracellular inactivation of sex steroids and their precursors and provides an important mechanism for maintenance of gender-dimorphic metabolism in the liver $(7,8)$. The androgen prehormone dehydroepiandrosterone (DHEA) is the preferred substrate for androgen ST (DST). In lean male mice, DST activity is suppressed at puberty, allowing unconjugated DHEA to be converted to potent androgens (4). In contrast, DST activity is not suppressed in livers of postpubertal lean females, promoting sequestration of

1. Abbreviations used in this paper: DHEA, dehydroepiandrosterone; DHEA-S, DHEA sulfate; DST, DHEA sulfotransferase; El, esterone E2-17 $\beta$-estradiol; EST, estrogen sulfotransferase; NIDDM, non-insulin-dependent diabetes mellitus; PAPS, 3'-phosphoadenosine-5"-phosphosulfate; PST, phenol sulfotransferase; ST, sulfotransferase; STS, sex steroid sulfohydrolase; UDPGT, UDP-glucuronyltransferase. 


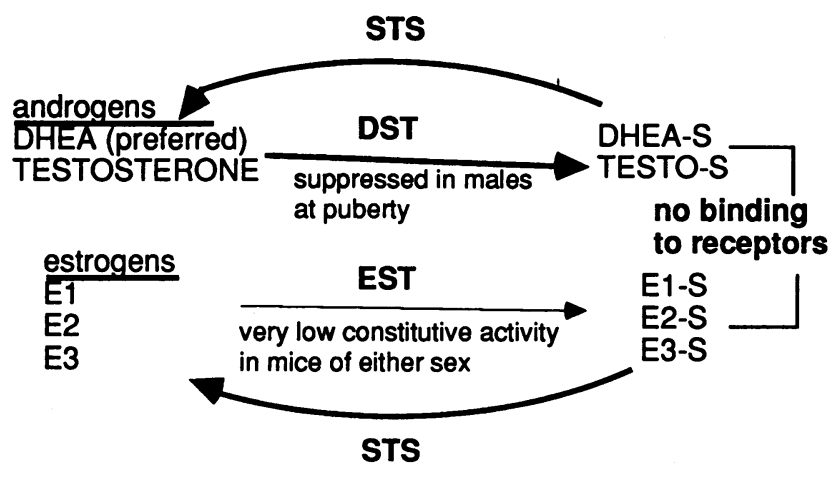

Figure 1. Sex steroid ST cycle in normal mice. The salient gender difference in lean mice is the male-specific suppression of the cytosolic androgen (DHEA-preferring, DST) ST at puberty. Cytosolic sulfurylation of estrogens by high affinity EST is barely detectable in lean mice of either sex. The reaction can be reversed by a microsomal STS present in liver of both sexes and with higher affinity for sulfated estrogens versus androgens. The cytosolic ST enzymes require PAPS as a sulfate donor.

sulfurylated preandrogens. At physiologic substrate concentrations, estrogen ST (EST) activity is barely detectable in livers of lean BKs mice of either sex (4). The $d b$ mutation markedly alters ST balance during the peripubertal period through induction of a high affinity, low $K_{\mathrm{m}}$ EST activity, followed by an aberrant suppression of DST activity in females (4). The accumulation of receptor-inactive estrogens in hepatocytes of both sexes, combined with failure to sequester hepatic androgens in females, results in a hyperandrogenized metabolism in BKs$d b / d b$ mice of both sexes.

The recent availability of rat cDNA probes for DST and EST permitted us to establish the chromosomal locations of the homologous loci in the mouse (Std and Ste, respectively) and to analyze the effect of $d b$ gene expression on the transcription of these two loci. Another St locus (Stp) encoding phenol ST has been mapped recently by us to mouse chromosome 7 (9). Expression of this gene is not associated with gender-dimorphic regulation of hepatic sex steroid metabolism. Thus, comparison of $d b$ gene effects on transcriptional activity of $S t$ genes encoding sex steroid ST versus phenol ST (PST) allowed determination as to whether the $d b$-St interactions required for diabesity were specific for the two $S t$ genes associated with regulation of hepatic sex steroid balance.

\section{Methods}

Gene mapping. Ste and Std were mapped by means of a panel of 94 DNAs prepared from an interspecific outcross between C57BL/6J (B6) and inbred Mus spretus, SPRET/Ei (SPRET), followed by one backcross (BC1) to SPRET. These DNA samples were obtained from the Genetic Mapping Resource of The Jackson Laboratory. A rat EST cDNA probe (10) was kindly provided by Dr. A. K. Roy (University of Texas, San Antonio, TX). Southern blot analysis using this probe with Bgl II-digested B6 versus SPRET genomic DNA demonstrated the presence of two linked ( $\sim 7$ and $9.1 \mathrm{~kb})$ restriction fragment variants not present in the SPRET genome. Hybridization conditions were as described previously; filters were washed three times in $0.1 \times$ SSC plus $0.1 \% \mathrm{SDS}$ at $50^{\circ} \mathrm{C}$ for $30 \mathrm{~min}$ per wash. Std was mapped using a full length rat hydroxysteroid ST cDNA probe (11) (designated 2-4 and kindly provided by Dr. C. N. Falany, University of Alabama, Birmingham, AL). Southern blot analysis using this probe with PvulI-digested B6 versus SPRET genomic DNA demonstrated the presence of eight linked restriction fragment variants not present in the SPRET genome. One of these B6-derived PvulI fragments $(\sim 7.4 \mathrm{~kb})$ allowed easy differentiation of the B6 versus SPRET allele in the BC1 DNA panel. Filters were hybridized as described above and washed twice in $0.1 \times$ SSC plus $0.1 \%$ SDS at $50^{\circ} \mathrm{C}$ and once at $55^{\circ} \mathrm{C}$ for $30 \mathrm{~min}$. The typing results were entered into The Jackson Laboratory Gene Mapping Resource database for identification of linkage association with previously mapped polymorphic loci in this DNA panel. This database contains a number of loci identified on the basis of motif sequence-tagged PCR products distinguishing the B6 from the SPRET genome (12).

Northern blot analysis. Total RNA was extracted from frozen livers using the single-step isolation method described by Chomczynski and Sacchi (13). Total RNA ( $10 \mu \mathrm{g})$ was electrophoretically separated in a $1.25 \%$ agarose gel containing $10 \mathrm{mM}$ sodium phosphate ( $\mathrm{pH} 6.5$ ), 3\% formaldehyde and transferred onto Zetabind (Cuno, Inc., Meridan, CT) by capillary transfer. The RNA was fixed onto the membrane by exposure to ultraviolet light $(1,200 \mu \mathrm{J} \times 100)$ using the Stratalinker (Stratagene, La Jolla, CA). The blot was hybridized simultaneously with ${ }^{32} \mathrm{P}$-labeled $\beta$-actin and the rat hydroxysteroid ST cDNA $2-4$ probe. The random hexamer radiolabeling, prehybridization, and hybridization procedures were as described previously (13). After a 24-h exposure, this blot was erased with boiling $0.2 \times$ SSC plus $0.1 \%$ SDS $2 \times$ $15 \mathrm{~min}$ and prehybridized before rehybridization with a radiolabeled rat PST (14), also provided by Dr. C. Falany. Finally, the rat EST cDNA (10) was used to generate a ${ }^{32} \mathrm{P}$-labeled cRNA probe by essentially using protocols and reagents supplied with Riboprobe ${ }^{\oplus}$ II core system (Promega Corp., Madison, WI). The presence of specific EST mRNA was determined by hybridization of the cRNA probe onto this filter. The hybridization was at $60^{\circ} \mathrm{C}$ for $24 \mathrm{~h}$ with $3 \times 30$-min washes in $0.1 \times \mathrm{SSC}, 0.1 \%$ SDS at $70^{\circ} \mathrm{C}$. The prehybridization and hybridization conditions were described by Watson et al. (15).

ST assays. Androgen ST (DST) and EST in cytosols were assayed as described previously (4). A modified protocol was used for assay of affinity-purified EST. Duplicate 25- $\mu$ l samples were added to $375 \mu \mathrm{l}$ of $0.05 \mathrm{M}$ Tris- $\mathrm{HCl}, \mathrm{pH} 7.5,0.01 \mathrm{M} \mathrm{MgCl}_{2}$ (buffer A), plus $100 \mu \mathrm{l}$ buffer A containing $250 \mu \mathrm{M}$ 3'-phosphoadenosine-5"-phosphosulfate (PAPS), $1.0 \mu \mathrm{M}$ estrone, and $\left[{ }^{3} \mathrm{H}\right]$ estrone (specific radioactivity $1.5 \mathrm{Ci} / \mathrm{mmol}$ ). Blank tubes contained the components except for PAPS, and the incubations were performed at $37^{\circ} \mathrm{C}$ for $10-30 \mathrm{~min}$. The assays were terminated by transferring the $0.5-\mathrm{ml}$ sample to $2.0 \mathrm{ml}$ of $3 \mathrm{M}$ sodium acetate buffer, $\mathrm{pH}$ 4.0. Each sample was vortexed for $30 \mathrm{~s}$ with $5 \mathrm{ml}$ anhydrous ether. After $2 \times 5-\mathrm{ml}$ extraction cycles, $0.5-\mathrm{ml}$ volume of aqueous product was counted for radioactivity using scintillation fluid (Aquasol II; New England Nuclear, Boston, MA).

EST was purified from liver tissue from 16 8-12-wk-old C57BL/ $\mathrm{KsJ}$ females. Livers were homogenized in four volumes $0.1 \mathrm{M}$ Tris$\mathrm{HCl}, \mathrm{pH} 7.5$, plus $0.25 \mathrm{M}$ sucrose in a Polytron (Brinkman Instruments, Inc., Westbury, NY). The cytosolic portion was clarified by ultracentrifugation for $40 \mathrm{~min}$ at $200,000 \mathrm{~g}$. The $35-55 \%\left(\mathrm{NH}_{4}\right)_{2} \mathrm{SO}_{4}$ insoluble-fraction was resuspended in $40 \mathrm{ml}$ of $0.01 \mathrm{M}$ Tris- $\mathrm{HCl}, \mathrm{pH}$ 7.5 , and dialyzed in the same buffer. The clarified dialysis retentate was added onto an equilibrated 70-ml DE52 DEAE cellulose column (2.8 $\mathrm{cm} \times 20 \mathrm{~cm}$ ) (Bio-Rad Laboratories, Melville, NY). Enzymatically active EST was eluted with two bed volumes of $0.05 \mathrm{M}$ Tris- $\mathrm{HCl}, \mathrm{pH}$ 7.5. The active fractions were pooled and loaded onto a 5-8- $\mathrm{ml}$ adenosine 3',5'-diphosphate agarose affinity column $(1.8 \mathrm{~cm} \times 10 \mathrm{~cm})$ (BioRad Laboratories) preequilibrated in $0.05 \mathrm{M}$ Tris- $\mathrm{HCl}, \mathrm{pH} 7.5$ (elution buffer). This adenosine 3',5'-diphosphate column was washed with three bed volumes elution buffer containing $0.13 \mathrm{M} \mathrm{KCl}$ and then with $10 \mathrm{ml}$ of buffer containing $20 \mu \mathrm{M}$ AMP, and finally reequilibrated in elution buffer. EST activity was eluted by running a linear $40-\mathrm{ml}$ gradient of 0-2.0 $\mu \mathrm{M}$ PAPS in elution buffer. 
Sex steroid sulfohydrolase (STS) and UDP-glucuronyltransferase (UDPGT) assays. Replicate pools of six to nine livers from C57BL/ $\mathrm{KsJ}-d b / d b$ or control mice were homogenized separately in $1.15 \%$ $\mathrm{KCl}$. The homogenates were centrifuged at $20,000 \mathrm{~g}$ for $20 \mathrm{~min}$ at $4^{\circ} \mathrm{C}$ and then were ultracentrifuged $200,000 \mathrm{~g}$ for $40 \mathrm{~min}$ at $4^{\circ} \mathrm{C}$. Microsomes were resuspended in $8.0 \mathrm{ml} 1.15 \% \mathrm{KCl}$, the protein concentration was determined, and 20 -mg aliquots were pelleted by ultracentrifugation and stored at $-70^{\circ} \mathrm{C}$ for up to 3 mo without loss of activity. STS was assayed using the procedure described in detail previously (16) with the following modifications. $20 \mathrm{mg}$ of $100,000 \mathrm{~g}$ washed microsomal pellets was resuspended in $2.0 \mathrm{ml}$ of $0.05 \mathrm{M}$ imidazole buffer, $\mathrm{pH}$ 7.2. These suspensions were diluted $1: 1$ with $0.05 \mathrm{M}$ imidazole, $\mathrm{pH} 7.2$, containing $2 \%$ Miranol detergent and solubilized by mixing for $30 \mathrm{~min}$ at room temperature. The solubilized portion was clarified by ultracentrifugation as described above. Replicate $50-\mu \mathrm{l}$ samples were assayed under saturating conditions for $40 \mathrm{~min}$ at $37^{\circ} \mathrm{C}$.

For glucuronyltransferase assay, mutant or control microsomal pellets $(20 \mathrm{mg}$ ) were resuspended in $0.6 \mathrm{ml}$ Tris- $\mathrm{HCl}, \mathrm{pH} 8.0$, containing $0.01 \mathrm{M} \mathrm{MgCl}_{2}$ (buffer $B$ ) and then diluted $1: 1$ with buffer $B, 20 \mathrm{mg} / \mathrm{ml}$ Lubrol PA detergent. The microsomes were solubilized by rotating this mixture for $\mathbf{3 0 ~ m i n ~ a t ~ r o o m ~ t e m p e r a t u r e , ~ a n d ~ t h e ~ s o l u b i l i z e d ~ p o r t i o n ~}$ was clarified by ultracentrifugation as described above. Replicate 100 $\mu \mathrm{l}$ samples were assayed for the isoforms of UDPGT under saturating conditions as described in detail by Falany and Tephly (17).

Reagents. $\left[1,2,6,7-{ }^{3} \mathrm{H}\right] \mathrm{DHEA}(70-100 \mathrm{Ci} / \mathrm{mmol}),\left[2,4,6,7-{ }^{3} \mathrm{H}\right]-$ estrone $(85-105 \mathrm{Ci} / \mathrm{mmol}),\left[6,7-{ }^{3} \mathrm{H}\right]$ estrone sulfate $(49 \mathrm{Ci} / \mathrm{mmol})$, $\left[7-{ }^{3} \mathrm{H}\right]$ DHEA sulfate $(16.3 \mathrm{Ci} / \mathrm{mmol}),\left[9,11-{ }^{3} \mathrm{H}\right]$ androsterone $(57$ $\mathrm{Ci} / \mathrm{mmol})$, and $\left[4-{ }^{14} \mathrm{C}\right]$ testosterone $(51.4 \mathrm{mCi} / \mathrm{mmol})$ were purchased from New England Nuclear. DHEA, estrone, estrone sulfate, DHEA sulfate, androsterone, testosterone, pregnenolone, $p$-nitrophenol, $17 \beta$-estradiol, $17 \alpha$-estradiol, PAPS, AMP, L- $\alpha$-phosphatidylcholine (type VII-E from egg yolk), UDP-glucuronic acid, and adenosine 3',5'-diphosphate agarose were purchased from Sigma Chemical Co. (St. Louis, MO). DE52 (DEAE cellulose) resin was purchased from Whatman Inc. (Fairfield, NJ). Lubrol PA detergent was a gift from Dr. Charles Falany, and the Miranol detergent was purchased from Miranol Inc. (Dayton, $\mathrm{NJ}$ ).

\section{Results}

Sex steroid St gene mapping. Hybridization of rat EST and DST cDNA probes to a panel of 94 Bgl II- and Pvull-digested DNAs made from $(B 6 \times$ SPRET $) \times$ SPRET backcross.mice localized the Ste gene (ST, estrogen-preferring) to the midpart of mouse Chromosome 5 and the Std gene (ST, DHEA-preferring) to the proximal region of Chromosome 7 . The map positions are schematically shown in Fig. 2 . The position of the Stp gene (ST, phenol-preferring) reported previously and located more distally on Chromosome 7 is also shown. Data in Table I show the recombination frequencies for the nearest linkage markers for Ste and Std. No recombinants were found between Ste and D5Birl, the latter marker positioned 45 centimorgan (cM) from the centromere on Chromosome 5. Similarly, no recombinants were found between $S t d$ and $P m v-4$, the latter marker positioned $2 \mathrm{cM}$ from the centromere on Chromosome 7. These mapping data formally exclude the possibility that the $d b$ mutation (on Chromosome 4) represents a variant Ste or Std gene.

The $d b$ gene and aberrant changes in St gene transcript concentrations. Northern blot analyses (Fig. 3) demonstrate the aberrant changes in hepatic $S t$ gene transcript concentrations elicited by the $d b$ mutation. Lean BKs- $m+/+d b$ (control) females, but not males, continue to transcribe DST mRNA after puberty. In contrast, $S t d$ transcript concentration
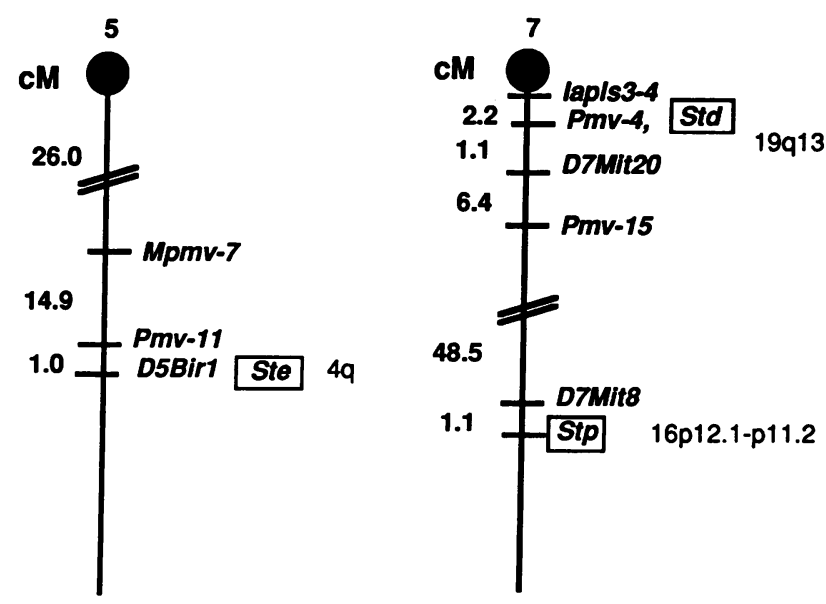

Figure 2. Chromosome linkage map showing the location of two sex steroid ST. ST, estrogen-preferring (Ste) maps to the midregion of mouse Chromosome 5, and the ST, DHEA-preferring ( $S t d)$ maps to the proximal part of Chromosome 7. The map position of an ST, phenol-preferring ( $S t p)$ locus previously mapped more distal on mouse Chromosome 7 (9) is also indicated. The presumed positions of homologous genes in the human genome are denoted on the right (the human homologue of Stp has indeed recently been mapped to 16p12.1-p11.2).

in BKs- $d b / d b$ females was reduced drastically. This decline in mRNA concentration correlates with the previously reported suppression of DST enzymatic activity $(4,6)$. This suppression of hepatic androgen sulfurylation capacity in mutant females is further exacerbated by the effect of $d b$ gene expression on hepatic Ste transcript levels. No constitutive EST mRNA transcripts are detected in liver of lean controls of either sex (Fig. 3 ). This represents a major genera difference between nonobese mice and rats, since in the latter androgen induction of an EST activity in male liver in addition to androgen suppression of DST is required to maintain a male-imprinted metabolic

Table I. Mapping of the Mouse ST, Estrogen-preferring (Ste) Gene to Chromosome 5 and ST, DHEA-preferring (Std) Gene to Chromosome 7 in a $(B 6 \times S P R E T) F 1 \times S P R E T$ First Backcross Typing Panel

\begin{tabular}{lccc}
\hline \multicolumn{1}{c}{ Interval } & $\begin{array}{c}\text { Recombinant/ } \\
\text { total }\end{array}$ & $\begin{array}{c}\text { Recombination } \\
\text { frequency } \\
(\times 100) \pm \text { SEM }\end{array}$ & $\begin{array}{c}95 \% \text { Confidence } \\
\text { limits } \\
\text { (lower-upper) }\end{array}$ \\
\hline Chromosome 5 & & & \\
Mpmv-7-Pmv-11 & $14 / 94$ & $14.89 \pm 3.67$ & $8.4-23.7 \mathrm{cM}$ \\
Pmv-11-Ste & $1 / 94$ & $1.06 \pm 1.06$ & $0-5.8 \mathrm{cM}$ \\
Ste-D5Bir1 & $0 / 83$ & 0 & $0-3.5 \mathrm{cM}$ \\
Chromosome 7 & & & \\
Iapls3-4-Pmv-4 & $2 / 92$ & $2.17 \pm 1.52$ & $0.3-7.6 \mathrm{cM}$ \\
Pmv-4-Std & $0 / 94$ & 0 & $0-3.1 \mathrm{cM}$ \\
Std-D7Mit20 & $1 / 94$ & $1.06 \pm 1.06$ & $0-5.8 \mathrm{cM}$ \\
D7Mit20-Pmv-15 & $6 / 94$ & $6.38 \pm 2.52$ & $2.4-13.4 \mathrm{cM}$ \\
& & & \\
\hline
\end{tabular}

$M p m v$ and $P m v$ are modified polytropic and polytropic murine leukemia viral loci, respectively (28); Iapls3-4 is an expressed intracisternal A-particle proviral element (29). D5Birl and D7Mit20 (=D7Mit24) microsatellite primers used in PCR to type the DNA panel have been described previously $(12,30)$. 
males females

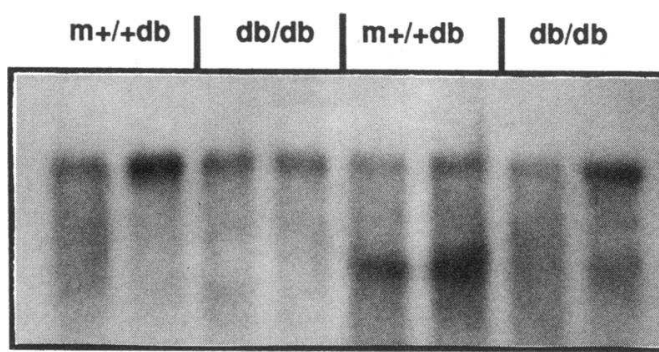

B-actin

DST

EST

PST

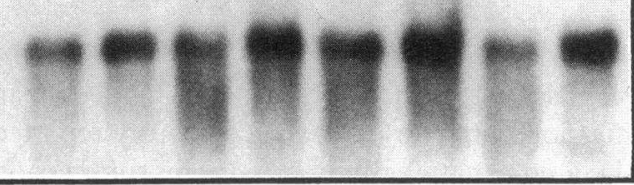

Figure 3. Northern analysis shows aberrant shifts in sex steroid ST mRNA concentrations in liver of $d b / d b$ mice. In the upper panel, total hepatic RNA from two 8-wk-old male and female normal or mutant mice is hybridized simultaneously with a $\beta$-actin and a DST probe. An anomalous suppression of the 1.1-kb Std transcript is evident in $d b / d b$ females in comparison with lean $(m+/+d b)$ female controls. The middle panel shows the same blot after rehybridization with an EST riboprobe. An anomalous interaction between Ste and the $d b$ mutation is indicated by the appearance of a $\sim 1.4-\mathrm{kb}$ transcript in $d b / d b$ mice of both sexes that is undetectable in lean littermate controls. The bottom panel shows the same blot after rehybridization with the PST probe. The $d b$ mutation did not interact with $S t p$ gene transcription, showing that $d b$ gene-induced transcriptional changes are specific for the two sex steroid ST.

pattern (10). In marked contrast to the absence of EST transcripts in the liver of lean BKs postpubertal males, EST transcripts are detected in $d b / d b$ mice of both sexes. In contrast to anomalous shifts in the transcriptional pattern of genes encoding sex steroid ST, no such interaction is observed between the $d b$ gene and the $S t p$ locus encoding the non-gender-dimorphic PST enzyme (Fig. 3). Hence, the diabetogenic interaction between the $d b$ mutation and $S t$ loci is specific for $S t$ loci controlling the balance of active androgens to estrogens in the liver.

The $d b$ gene induces a specific EST hepatic isoform. It was heretofore unknown whether the high activity, low $K_{\mathrm{m}}$ EST hepatic isoform previously reported in BKs- $d b / d b$ liver represented the specific product of de novo Ste gene induction, or instead, an allosteric modification of a preexisting general specificity ST (such as PST) so that its affinity for estrogen binding was increased. To correlate the action of the $d b$ gene on Ste gene activation with expression of EST, an effort was made to purify a $d b$-specific EST activity. Consistent with the absence of mRNA transcripts in liver of lean BKs controls, an estrogenspecific ST could not be purified using the protocol described in Methods. As shown in Table II, an EST with high affinity for estrogen, but not DHEA or dihydrotestosterone sulfurylation at the $3 \beta$-hydroxy position, was purified from hepatic cytosol of BKs- $d b / d b$ females. No DST activity copurified with this $d b$ gene-induced enzyme. This EST activity, purified over 2,000-fold from that present in crude cytosol, exhibited a $K_{\mathrm{m}}$ for estrone E2-17 $\beta$-estradiol (E1) between 0.02 and $0.04 \mu \mathrm{M}$; $V_{\max }$ was $0.2 \mu \mathrm{M}$. The inability of $2 \mu \mathrm{M}$ DHEA (the favored substrate of DST) or $2 \mu \mathrm{M}$ para-nitrophenol (a favored substrate of PST) to compete with $0.2 \mu \mathrm{M}$ E1 for binding to affinity-purified enzyme confirms the induction of an EST isoform specific for estrogens, instead of allosteric modification of a preexisting ST activity with broad substrate specificity. Silver staining of SDS-polyacrylamide gels of the affinity columnpurified EST activity showed the presence of three bands with molecular masses of $\sim 29,31$, and $34 \mathrm{kD}$, approximating the 31-kD molecular mass reported for the rat hepatic EST (10). This enzyme activity was highly unstable after ion exchange and Sephadex column chromatographic purification.

In addition to sulfurylation, glucuronidation represents an important pathway for sex steroid conjugation in the liver. Hence, if the trans-activation of the Ste locus induced by the $d b$ mutation reflected a generalized increase in estrogen catabolism, an increase in microsomal estrogen glucuronidation would also be anticipated. This was not the case. UDPGT activities were not elevated in $d b / d b$ microsomes when androsterone $(50 \mu \mathrm{M})$, testosterone $(80 \mu \mathrm{M})$, or E1 $(50 \mu \mathrm{M})$ were used as substrates (data not shown). STS, encoded by the Sts locus expressed on both male and female sex chromosomes in the mouse, represents another microsomal enzyme associated with the sulfurylation pathway. This constitutively expressed enzyme desulfurylates sex steroids, such that if the $d b$ gene cocomitantly induced an EST enzyme and increased STS activity, a futile cycle would be maintained (18). Under these conditions,

Table II. Determination of 3 $\beta-O H$ Estrogen Specificity of Affinity-purified C57BL/KsJ-db/db Female Liver EST by Competitive Substrate Assay

\begin{tabular}{llr}
\hline \multicolumn{1}{c}{ Substrate } & \multicolumn{1}{c}{$3 \mathrm{C}, 17 \mathrm{C}$ Position } & $\begin{array}{c}\text { Percentage of } \\
\text { activity remaining }\end{array}$ \\
\hline $17 \beta$-Estradiol & $3 \beta-\mathrm{OH}, 17 \beta-\mathrm{OH}$ & 9 \\
$17 \alpha$-Estradiol & $3 \beta-\mathrm{OH}, 17 \alpha-\mathrm{OH}$ & 1 \\
Estrone & $3 \beta-\mathrm{OH}, 17-\mathrm{keto}$ & 1 \\
Estrone sulfate & $3 \beta-\mathrm{SO}, 17-\mathrm{keto}$ & 70 \\
Dihydrotestosterone & $3 \beta-\mathrm{keto}, 17 \beta-\mathrm{OH}$ & 100 \\
DHEA & $3 \beta-\mathrm{OH}, 17-\mathrm{keto}$ & 92 \\
Androsterone & $3 \alpha-\mathrm{OH}, 17-\mathrm{keto}$ & 80 \\
Pregnenolone & $3 \beta-\mathrm{OH}$ & 102 \\
$p$-Nitrophenol & \multicolumn{1}{c}{} & \\
& &
\end{tabular}

The specific activity of the affinity-purified EST was $13 \mathrm{nmol} / \mathrm{mg}$ per minute. Saturating concentration of $0.2 \mu \mathrm{M}$ estrone ( $100 \%$ activity) was competed with $2.0 \mu \mathrm{M}$ of the various substrates. 
the net level of active tissue estrogens would not differ from the low levels found in normal mice. In fact, no difference between STS activity in hepatic microsomes from BKs lean versus $d b /$ $d b$ mice was observed (data not shown), demonstrating that the consequence of elevated intracellular EST activity would indeed be estrogen inactivation.

\section{Discussion}

The present study demonstrates that obesity gene-mediated diabetogenesis in BKs- $d b / d b$ mice entails aberrant trans-regulation of ST genes whose products control the ratio of functional androgens and estrogens in the liver. The induction of a high affinity EST in mutant mice of both sexes, coupled with loss of ability to sulfurylate androgens in females, would effectively produce a hyperandrogenized metabolic milieu. Estrogens potentiate glucose homeostasis in rodents in part by increasing the density of hepatocyte surface insulin receptors, while androgens antagonize these estrogenic effects (19). Insulin resistance produced by the $d b$ mutation has been associated with a marked decrease in the number of hepatocyte plasma membrane insulin receptors (20). This decrease could potentially reflect the decreased ratio of intracellular estrogens to androgens resulting from the inactivation of free estrogens by the induction of the high affinity EST and the suppression of the androgen-inactivating DST. The ability of two unlinked recessive obesity mutations ( $d b$ and $o b$ [obese, Chromosome $6]$ ) to induce severe diabetes in BKs females correlates with the ability of each mutation to increase estrogen inactivation while suppressing androgen inactivation (6). The net effects of these pleiotropic changes in gene expression would be a hyperandrogenized hepatic metabolic state. BKs females homozygous for a third recessive obesity gene, fat (fat, Chromosome 8), are diabesity resistant, despite development of comparable obesity and hyperinsulinemia to that produced by the diabetogenic $d b$ and $o b$ mutations $(6,21)$. BKs-fat / fat females do not exhibit the virilizing shifts in DST and EST activities characteristic of BKs- $d b / d b$ and $-o b / o b$ females (6). Thus, the diabetogenic potential of obesity mutations in BKs females correlates well with the ability to produce the hyperandrogenic shifts described above. Further confirmation of the diabetogenic significance of these hyperandrogenic shifts is provided by analysis of the diabesity resistance of $\mathrm{C} 3 \mathrm{HeB} / \mathrm{FeJ}-d b / d b$ females versus susceptibility of BKs- $d b / d b$ females. Unlike the BKs inbred strain background, genetic modifiers in the $\mathrm{C} 3 \mathrm{HeB} / \mathrm{FeJ}$ background prevent induction of the high affinity EST hepatic isoform in mice of either sex (4). The sexually dimorphic diabesity observed in $\mathrm{C} 3 \mathrm{HeB} / \mathrm{FeJ}-d b / d b$ males requires testicular androgen secretion since adolescent castration prevented diabesity in these males (4). In contrast, in BKs- $d b / d b$ males, increases in the level of mRNA transcripts from the Ste locus encoding the high affinity EST isoform apparently provide sufficient disturbance of the androgen/estrogen balance so that diabesity can develop independently of testicular-derived androgens. Thus, the ability of the $d b$ mutation to modify the concentration of Ste transcripts encoding the EST isoform associates strongly with differential inbred strain background susceptibility to diabesity and provides important insight as to the nature of the background genomic modifiers required for diabetogenesis.
Hyperinsulinemia is one of the earliest pathophysiologic markers of the disturbed metabolism produced by most murine obesity-producing mutations. BKs- $d b / d b$ mice develop hyperinsulinemia by day 10 postpartum, before development of insulin resistance, obesity, and hyperglycemia demonstrable during the peripubertal period shortly after weaning (22). At day 10 postpartum, DST was active in hepatic cytosols of normal and mutant mice of both sexes. Induction of the mutant genotype-restricted high affinity EST activity was not detectable until day 17 postpartum (4). Although hyperinsulinemia progressively becomes more severe with increasing age, the absence of EST induction in severely hyperinsulinemic BKs-fat/ fat mutants indicates that some factor other than hyperinsulinemia is required to activate Ste gene transcription. This factor is very likely to be corticosterone, the major adrenal glucocorticoid in mice. Interestingly, hypercorticosteronemia, an endocrinopathy associated with diabesity in BKs- $d b / d b$ and $-o b / o b$ mice, has not been observed in an incipient congenic stock of diabesity-resistant BKs-fat/fat mice (23). Implantation of dexamethasone into diabesity-resistant VY- $A^{v y}$ females induced a transient hyperglycemia accompanied by induction of a high affinity EST (24). This rapid induction of enzyme activity was accompanied by the appearance of mRNA transcripts not detectable in dexamethasone-untreated mice of any genotype (24). Since in the present studies nuclear runoff analysis was not performed, we cannot confirm that the failure to detect Ste mRNA in total hepatic RNA from wild-type BKs mice was because of an inactive gene versus an unstable mRNA. However, the magnitude of the dexamethasone-elicited increase in Ste transcript concentration in $A v y / a$ female mice is typical of other dexamethasone-inducible transcriptional activations. Indeed, recent unpublished experiments in which $0.5 \mathrm{mg}$ dexamethasone pellets were implanted subcutaneously into diabesity-resistant BKs- fat / fat females elicited an identical response as observed in diabesity-resistant $A v y /$ a females: severe hyperglycemia within $72 \mathrm{~h}$ accompanied by induction of high levels of hepatic EST. Thus, it is reasonable to propose that the interaction between a diabetogenic obesity gene and the Ste locus entails transcriptional activation in response to hypercorticosteronemia. It must be emphasized that the presence of the obesity mutation on a susceptible inbred strain background, in addition to hypercorticism, was required to achieve inappropriately high levels of hepatic glucose output and ensuing hyperglycemia. This point is illustrated forcefully by the fact that, while dexamethasone elicited induction of EST mRNA and enzyme activity into both obese VY- $A v y / a$ and BKs-fat / fat females and their lean littermate controls, hyperglycemia developed only in females expressing the obesity mutations.

The present results are of particular interest in that certain important modifier genes underlying susceptibility to diabesity appear not to represent activity variants of possible candidate genes encoding enzymes of carbohydrate or fat metabolism (such as glucokinase, glycogen synthetase, or lipoprotein lipase ). Rather, $d b$ gene-induced diabesity is conferred, in part, by inducing aberrant trans-regulation of "normal" genes whose products control the ratio of active hepatic androgens and estrogens. In this respect, the insulin resistance present in the BKs- $d b / d b$ mice may share pathogenetic features with certain hyperandrogenism syndromes associated with glucose intolerance in obese humans. Hyperandrogenization of tissues (liver, fat, muscle) frequently accompanies development of the 
abdominal (visceral) forms of obesity that so strongly predispose humans to severe glucose intolerance and NIDDM (24a). Postmenopausal declines in ovarian estrogen production in human females, coupled with increased gonadotrophin release from the pituitary, may elicit excessive ovarian androgen production (polycystic ovary syndrome). The polycystic ovary syndrome is often accompanied by obesity, hyperinsulinemia, peripheral insulin insensitivity, reduced hepatic insulin extraction, and sometimes $\operatorname{NIDDM}(1,24 a)$.

DST activity is present in the liver of human females, and the human gene has been cloned. Based upon the known conservation of syntenic regions between the region of mouse Chromosome 7 containing the Std locus and human Chromosome $19 q$, we predict that the human locus is found on this chromosome. Although EST is expressed in human fetal and placental tissues, a high affinity EST has not been reported in adult human liver. Based upon syntenic considerations, a human homologue of Ste (mouse Chromosome 5) should be located on human Chromosome $4 \mathrm{p}$. Indeed, the mouse chromosomal location of Stp on distal Chromosome 7 accurately predicted the location of the human homologue on Chromosome 16p. The fact that no EST activity has been found in liver of normal human females does not exclude the possibility that a human Ste locus exists that is not expressed constitutively in adult life. We have been unable to detect Ste transcripts in normal BKs mice of either sex. In normal Sprague-Dawley rats, the gene is transcribed only in postpubertal males, although gene transcription could be induced by dihydrotestosterone treatment of ovariectomized females. The possibility that induction of a constitutively silent EST-encoding gene occurs in livers of hyperandrogenized females is inherently difficult to test because of the requirement for liver biopsy. Hyperandrogenization in humans is inferred when increased serum testosterone levels are found in conjunction with decreased serum concentrations of DHEA sulfate (DHEA-S) and/or sex hormone-binding globulin $(25,26)$. Although high concentrations of sex steroids and their transport molecules in plasma may reflect the quantity of hormone available for specific biologic effects in target tissues, they are not direct indicators of levels of receptor-active steroids within cells. Indeed, steroidogenic enzymes capable of forming active sex steroids from receptor-inactive precursors ("intracrines" such as DHEA or $\Delta 4$-androstenedione) are contained in a variety of extragonadal tissues, such that serum levels of hormones serve primarily as an index of gonadal or adrenal activity. In contrast to the human adrenal, the mouse adrenal does not secrete either DHEA or DHEA-S (27). Rather, the mouse (and the rat) appears to regulate hepatic androgen/estrogen balance primarily via inactivation by specific intracellular enzymes (7). Thus, reduced intracellular DHEA-S in livers of $d b / d b$ mice is not achieved by decreased output from the adrenal but instead via transcriptional suppression of the Std locus. This, in turn, appears to be a consequence of intracellular estrogen inactivation resulting from Ste gene expression, since active estrogens are required for continued expression of DST activity in postpubertal females (4). In summary, the present analysis identifies a new genetic mechanism underlying hyperandrogenicity development in a mouse model of NIDDM.

\section{Acknowledgments}

The authors gratefully acknowledge Dr. Edward Birkenmeier and Ms. Lucy Rowe of The Jackson Laboratory for providing The Jackson Lab- oratory Gene Mapping Resource DNA panels and for providing unpublished genetic typing information. We thank Dr. Wayne Frankel and Dr. Verity A. Letts (The Jackson Laboratory) for providing typing information for the retroviral loci and Ms. Dean Turner for providing typing information for D7Mit20.

This work was supported by National Institutes of Health grant DK-17631 and a grant from the Diabetes Research and Education Foundation.

\section{References}

1. Kissebah, A. H., and A. N. Peiris. 1989. Biology of regional body fat distribution: relationship to non-insulin dependent diabetes mellitus. Diabetes Metab. Rev. 5:83-109.

2. Shafrir, E. 1992. Animal models of non-insulin dependent diabetes. Diabetes Metab. Rev. 8:179-208.

3. Leiter, E. H. 1989. The genetics of diabetes susceptibility in mice. FASEB (Fed. Am. Soc. Exp. Biol.) J. 3:2231-2241.

4. Leiter, E. H., H. D. Chapman, and D. L. Coleman. 1989. The influence of genetic background on the expression of mutations at the diabetes locus in the mouse. V. Interaction between the $\mathrm{db}$ gene and hepatic sex steroid sulfotransferases correlates with gender-dependent susceptibility to hyperglycemia. Endocrinology 124:912-922.

5. Leiter, E. H., W. G. Beamer, D. L. Coleman, and C. Longcope. 1987. Androgenic and estrogenic metabolites in serum of mice fed dehydroepiandrosterone: relationship to anti-hyperglycemic effects. Metab. Clin. Exp. 36:863-869.

6. Leiter, E., H. Chapman, and C. Falany. 1991. Synergism of obesity genes with hepatic steroid sulfotransferases to mediate diabetes in mice. Diabetes. 40:1360-1363.

7. Roy, A. 1992. Regulation of steroid hormone action in target cells by specific hormone-inactivating enzymes. Proc. Soc. Exp. Biol. Med. 199:265-272

8. Falany, C. N. 1991. Molecular enzymology of human liver cytosolic sulfotransferases. Trends Pharmacol. Sci. 12:255-259.

9. Dooley, T., R. Obermoeller, E. Leiter, H. Chapman, C. Falany, Z. Deng, and M. Siciliano. 1993. Mapping of the phenol sulfotransferase gene (STP) to human chromosome 16p12.1-p11.2 and to mouse chromosome 7. Genomics. 18:440-443.

10. Demyan, W., C. Song, D. Kim, S. Her, W. Gallwitz, T. Rao, M. Slomczynska, B. Chatterjee, and A. Roy. 1992. Estrogen sulfotransferase of the rat liver: complementary DNA cloning and age- and sex-specific regulation of messenger RNA. Mol. Endocrinol. 6:589-597.

11. Comer, K., J. Falany, and C. Falany. 1993. Cloning and expression of human liver dehydroepiandrosterone sulphotransferase. Biochem. J. 289:233240.

12. Birkenmeier, E., U. Schneider, and S. Thurston. 1992. Fingerprinting genomes by use of PCR with primers that encode protein motifs or contain sequences that regulate gene expression. Mamm. Genome. 3:537-545.

13. Hamaguchi, K., H. R. Gaskins, and E. H. Leiter. 1991. NIT-1, a pancreatic $\beta$ cell line established from a transgenic NOD/Lt mouse. Diabetes. 40:842849.

14. Hirshey, S., T. Dooley, I. Reardon, R. Heinrikson, and C. Falany. 1992. Sequence analysis, in vitro translation, and expression of the cDNA for rat liver minoxidil sulfotransferase. Mol. Pharmacol. 42:257-264.

15. Watson, G., M. Felder, L. Rabinow, K. Moore, C. Labarca, C. Tietze, G. Vander Molen, L. Bracey, M. Brabant, J. Cai, and K. Paigen. 1985. Properties of rat and mouse $\beta$-glucuronidase mRNA and cDNA including evidence for sequence polymorphism and genetic regulation of mRNA levels. Gene (Amst.). 36:15-25.

16. Leiter, E. H., P. H. Le, and D. L. Coleman. 1987. Susceptibility to db gene and streptozotocin-induced diabetes in C57BL mice: control by gender-associated, MHC-unlinked traits. Immunogenetics. 26:6-13.

17. Falany, C., and T. Tephly. 1983. Separation, purification, and characterization of three isoenzymes of UDP-glucuronyltransferase from rat liver microsomes. Arch. Biochem. Biophys. 227:248-258.

18. Kauffman, F. C., M. Whittaker, I. Anundi, and R. G. Thurman. 1991 Futile cycling of a sulfate conjugate by isolated hepatocytes. Mol. Pharmacol. 39:414-420.

19. Krakower, G., D. Meier, and A. Kissebah. 1993. Female sex hormones, perinatal, and peripubertal androgenization on hepatocyte insulin dynamics in rats. Am. J. Physiol. 264(Endocr. Metab. 27):E342-E347.

20. Meyerovitch, J., P. Rothenberg, Y. Schechter, S. Bonner-Weir, and C. R. Kahn. 1991. Vanadate normalizes hyperglycemia in two mouse models of noninsulin-dependent diabetes mellitus. J. Clin. Invest. 87:1286-1294.

21. Coleman, D. L., and E. M. Eicher. 1990. Fat (fat) and tubby (tub), two autosomal recessive mutations causing obesity syndromes in the mouse. $J$. Hered. 81:424-427. 
22. Coleman, D. L., and K. P. Hummel. 1974. Hyperinsulinemia in preweaning diabetes $(\mathrm{db})$ mice. Diabetologia. 10:607-610.

23. Leiter, E. 1993. Obesity genes and diabetes induction in the mouse. Crit. Rev. Food Sci. Nutr. 33:333-338.

24. Gill, A. M., E. H. Leiter, J. G. Powell, H. D. Chapman, and T. T. Yen 1994. Dexamethasone-induced hyperglycemia in obese $A^{\text {vy }} / a$ (viable yellow) female mice entails preferential induction of a hepatic estrogen sulfotransferase. Diabetes. In press.

24a. Bjorntorp, P. 1993. Androgens, the metabolic syndrome, and non-insulin dependent diabetes mellitus. Ann. NY Acad. Sci. 676:242-252.

25. Lindstedt, G., P.-A. Lundberg, L. Lapidus, H. Lundgren, C. Bengtsson, and P. Bjorntorp. 1991. Low sex-hormone-binding globulin concentration as independent risk factor for development of NIDDM. Diabetes. 40:123-128.
26. Nestler, J., J. Clore, and W. Blackard. 1992. Dehydroepiandrosterone: the "missing link" between hyperinsulinemia and atherosclerosis? FASEB (Fed. Am. Soc. Exp. Biol.) J. 6:3073-3075.

27. van Weerden, W., H. Blerings, G. van Steenbrugge, F. de Jong, and F. Schroder. 1992. Adrenal glands of mouse and rat do not synthesize androgens. Life Sci. 50:857-861.

28. Frankel, W., J. Stoye, B. Taylor, and J. Coffin. 1990. A genetic linkage map of endogenous murine leukemia proviruses. Genetics. 124:221-236.

29. Lueders, K., W. Frankel, J. Mietz, and E. Kuff. 1993. Genomic mapping of intracisternal A-particle proviral elements. Mamm. Genome. 4:69-77.

30. Dietrich, W., H. Katz, S. Lincoln, H.-S. Shin, J. Friedman, N. Dracopoli, and $E$. Lander. 1992. A genetic map of the mouse suitable for typing intraspecific crosses. Genetics. 131:423-447. 